\title{
The Unmet Supportive Care Needs of Omani Women Diagnosed with Breast Cancer
}

"Mohammed Al-Azri, ${ }^{1}$ Khalid Al-Bimani, ${ }^{2}$ Al-Anoud Al-Maqbali, ${ }^{3}$ Hala Al-Riyami, ${ }^{3}$ Al-Kuthar Al-Shabnooti, Sathiya M. Panchatcharam, ${ }^{4}$ Sanjay Jaju

ABSTRACT: Objectives: This study aimed to assess the unmet supportive care needs of Omani women with breast cancer (BC). Methods: This cross-sectional study was conducted from November 2020 to February 2021 among 250 adult Omani women diagnosed with BC at Sultan Qaboos University Hospital, Muscat, Oman. An Arabic version of the 34-item Supportive Care Needs Survey-Short Form tool was used to determine perceived unmet supportive care needs across five domains. Results: A total of 181 women participated in the study (response rate: $72.4 \%$ ). The domain with the highest mean score per item was health system and information (mean score: 3.33), with the greatest unmet need in this domain being information about what the patient could do to help themselves get well (40.9\%). The domain with the second highest mean score per item was patient care and support (mean score: 3.04), with the greatest unmet need being for clinicians to be more sincere with the patient (36.5\%). Higher total mean scores were reported by women who had visited the hospital four times or more over the two months preceding the study $(P=0.045)$, those with stage 3 or 4 cancer $(P=0.047)$ and those who had recently undergone radiotherapy or chemotherapy $(P=0.014)$. Conclusion: Most unmet supportive care needs fell under the health system and information domain. Healthcare providers in Oman should explore patient concerns and provide sufficient information at various stages of the care process to decrease the anxiety associated with living with cancer.

Keywords: Breast Neoplasms; Needs Assessment; Palliative Supportive Care; Women; Oman.

\section{ADVANCES IN KNOWLEDGE}

To the best of the authors' knowledge, this is the first study to assess the unmet supportive care needs of Omani women diagnosed with breast cancer $(B C)$.

The most frequently reported unmet supportive care needs were informational in nature, while the greatest unmet psychological need was how to deal with the fear of cancer recurrence.

Women most frequently reported needing greater sincerity from their clinicians and more help with sleeping issues but were less concerned regarding unmet sexual needs.

Significantly higher unmet supportive care needs were reported by women who had recently received radiotherapy or chemotherapy.

\section{Application to Patient Care}

The findings of this study indicate an urgent need to improve existing informational support services for Omani women with BC and to incorporate psychological support services into routine oncology practice.

Clinicians should consider improving patient-clinician communication and adopting a patient-centred care approach during consultations to help address the unmet care needs of women with BC in Oman. This may help reduce the rate of related psychological comorbidities such as depression, anxiety and stress.

$\mathrm{S}$ UPPORTIVE CARE REFERS TO A PATIENTcentred approach to care in which necessary services are provided to meet the emotional, social, informational and spiritual needs of patients with serious illnesses. ${ }^{1,2}$ Patient-centred care is recognised as a benchmark of quality in cancer care, with the delivery of supportive care services deemed just as important as that of curative or palliative cancer treatments. ${ }^{3}$ Thus, while cancer treatment is essential to cure the patient and increase their likelihood of survival, supportive care is considered necessary to improve their quality of life.
In recent years, there has been a shift in focus from treatment to supportive care to help patients cope with the experience of living with cancer., The supportive care requirements of cancer patients have been categorised into six domains: health system and information, patient care, treatment, psychosocial, sexual and financial needs. ${ }^{5}$ A greater understanding of the supportive care needs of cancer patients can help to identify specific challenges and concerns. ${ }^{6}$ On the other hand, failure to meet these needs can interfere with the patient's comfort, quality of life, treatment decision-making abilities and adherence to treatment. ${ }^{7}$ 
A study on Chinese patients with breast and colorectal cancer showed that both types of patients most commonly experienced unmet needs in the health system and information domains, with younger patients having more frequent unmet needs in the sexual and health system and information domains. ${ }^{6}$ On the other hand, a recent study conducted in the United Arab Emirates (UAE) showed that the most prevalent unmet supportive care needs rated at a moderate-to-high level by patients with different cancers were in the psychological domain, while needs in the sexual domain were least frequently reported. ${ }^{8}$

In Oman, breast cancer (BC) is a leading cause of death and disability, accounting for $12.79 \%$ of all cancers and $24.50 \%$ of all female cancers. ${ }^{9}$ As a result of increased life expectancy, urbanisation and the adoption of more Westernised lifestyles, the incidence of $\mathrm{BC}$ in Oman has almost doubled over the last two decades. ${ }^{10}$ Moreover, most women with $\mathrm{BC}$ in Oman are diagnosed at a younger age and at a later stage compared to those in Western countries, with an average five-year survival rate of $63 \% .{ }^{10,11}$ Previous studies have shown that Omani women diagnosed with $\mathrm{BC}$ are at risk of adverse physical and psychosocial morbidities. ${ }^{4,12,13}$ However, no study has yet attempted to assess the unmet supportive care needs of Omani women diagnosed with $\mathrm{BC}$. Identifying and addressing the unmet supportive care needs of cancer patients is imperative to help improve their quality of life. ${ }^{6}$

\section{Methods}

This cross-sectional questionnaire study was conducted from November 2020 to February 2021 at the Sultan Qaboos University Hospital (SQUH), Muscat, Oman, a referral teaching and training hospital that provides comprehensive oncological treatment to $\mathrm{BC}$ patients. Adult Omani women aged $\geq 18$ years who had been diagnosed with any stage of $\mathrm{BC}$ over the past five years at SQUH were identified from the electronic hospital information system. According to official data from the Ministry of Health, there were 274 BC cases in Oman in 2017. ${ }^{14}$ Thus, assuming a prevalence of $50 \%$ of unmet supportive care needs in five domains, with a precision rate of $5 \%$ and desired confidence interval of $95 \%$, the necessary sample size for the study was calculated to be 170 participants. However, to compensate for non-respondents, a total of 250 patients were invited to participate in the study via telephone or e-mail according to the contact information available in the system.

A previously validated Arabic version of the 34-item Supportive Care Needs Survey-Short Form
(SCNS-SF34) was used to collect data regarding the respondents' unmet supportive care needs. ${ }^{8}$ The original SCNS-SF34 is a validated instrument used as part of routine cancer care to measure cancer patients' perceived unmet supportive care needs across five domains, including psychological (10 items), health system and information (8 items), patient care and support (6 items), physical and daily living (5 items), sexuality (2 items) and other (3 items) needs. ${ }^{15}$ Originally, the data were intended to be collected using a paper-based questionnaire; however, due to the ongoing COVID-19 pandemic, research assistants were prohibited from entering SQUH and having direct contact with patients to minimise the risk of transmission. Thus, the Arabic version of the SCNSSF34 tool was modified so that it could be accessed and completed electronically by literate participants. For illiterate participants, the questionnaires were completed by a researcher based on the information collected during telephone interviews.

Participants were asked to rate their perceived level of need for additional support for each item on a five-point scale. The internal consistency of the original SCNS-SF34 tool has been found to be high (Cronbach's alpha coefficient range: $0.86-0.96) .{ }^{15}$ In addition, the tool has been translated into various languages and used in different populations worldwide., ${ }^{5,16,17}$ Nair et al. translated the SCNS-SF34 into Arabic for use in the UAE, a neighbouring country to Oman. ${ }^{8}$ In addition, a pilot study was conducted on the first 30 participants to determine the reliability and clarity of the Arabic version of the SCNS-SF34 questionnaire used in the present study. This revealed Cronbach's alpha coefficients of 0.90, 0.92, 0.83, 0.87 and 0.94 for the psychological, health system and information, patient care and support, physical and daily living and sexuality domains of unmet supportive care needs, respectively.

Collected data were analysed using the Statistical Package for the Social Sciences (SPSS), Version 25.0 (IBM Corp., Armonk, New York, USA). For descriptive purposes, categorical variables were presented as numbers and percentages, while continuous variables were presented as means and standard deviations or standard errors of measurement. Frequencies of ratings for individual items were calculated to determine the items most and least commonly reported to have a high level of unmet need in each domain. Associations between continuous and categorical variables were compared using an independent t-test or analysis of variance. A $P$ value of $<0.05$ was considered statistically significant.

The study has been approved by the Medical Research and Ethics Committee of the College 
of Medicine and Health Sciences, Sultan Qaboos University (MREC \#2189). All study procedures conformed to the tenets of the Declaration of Helsinki. Written informed consent was obtained from all respondents prior to their participation in the study.

\section{Results}

Of the 250 women with $\mathrm{BC}$ invited for the study, a total of 181 agreed to participate (response rate: $72.4 \%$ ). The mean age was $47.5 \pm 10.6$ years, with most participants being $41-50$ years old (44.4\%), married (72.9\%) and educated to the university level or higher (40.3\%). Most women were unemployed (58.0\%) and had a monthly household income of $\leq 500$ Omani rials (56.4\%). Over one-third (35.9\%) were residents of Muscat and a quarter $(25.4 \%)$ reported a family history of BC. The majority of women $(70.2 \%)$ had been diagnosed with $\mathrm{BC}$ more than two years prior and at an advanced stage (stage 3 or $4 ; 42.2 \%$ ). A total of 78 (44.1\%) patients had recently undergone chemotherapy or immunotherapy [Table 1].

Across the five domains of unmet supportive care needs, the domain with the highest mean score per item was health system and information (3.33 \pm 0.09$)$, followed by patient care and support (3.04 \pm 0.08$)$, physical and daily living (2.90 \pm 0.08$)$, psychological $(2.77 \pm 0.08)$ and sexuality $(2.27 \pm 0.10)$ [Table 2]

The mean total score for items in the psychological domain was $27.70 \pm 10.33$. Overall, the item most frequently perceived by respondents as associated with a high level of unmet need in this domain was fears about cancer recurrence (34.3\%), followed by fears about cancer spreading (33.7\%) and fears about children or people close to the patient (32.6\%). The least frequently reported items included fears about the patient's loss of independence (5.0\%), concerns regarding the ability of those close to the patient to cope with their care (11.6\%) and thoughts about death (11.6\%).

The mean total score for items in the physical and daily living domain was $14.51 \pm 5$.40. Items most frequently reported as having a high level of unmet need included not sleeping well (16.0\%) and not being able to continue with the activities that the patient had engaged in before being diagnosed with cancer (15.5\%). In contrast, fewer participants reported a high level of unmet need for items such as pain (9.9\%) and nausea/vomiting (9.9\%).

The mean total score for items in the health system and information domain was $26.64 \pm 9.42$. The need to be informed about what the patient could do to help themselves get well was most frequently found to be unmet at a high level (40.9\%), followed by the
Table 1: Sociodemographic and clinical characteristics of Omani women diagnosed with breast cancer $(\mathrm{N}=181)$

\begin{tabular}{|c|c|}
\hline Characteristic & n (\%) \\
\hline \multicolumn{2}{|l|}{ Age in years* } \\
\hline$\leq 30$ & $10(5.6)$ \\
\hline $31-40$ & $30(16.7)$ \\
\hline $41-50$ & $80(44.4)$ \\
\hline $51-60$ & $41(22.8)$ \\
\hline$>60$ & $19(10.6)$ \\
\hline \multicolumn{2}{|l|}{ Education level $^{\dagger}$} \\
\hline Illiterate (cannot read or write) & $28(15.5)$ \\
\hline Completed primary school (grade 6) & $10(5.5)$ \\
\hline Completed intermediate school (grade 9) & $13(7.2)$ \\
\hline Completed secondary school (grade 12) & $57(31.5)$ \\
\hline Completed university & $63(34.8)$ \\
\hline Completed postgraduate/doctorate & $10(5.5)$ \\
\hline \multicolumn{2}{|l|}{ Marital status } \\
\hline Married & $132(72.9)$ \\
\hline Single & $13(7.2)$ \\
\hline Widowed & $12(6.6)$ \\
\hline Divorced & 24. (13.3) \\
\hline \multicolumn{2}{|l|}{ Place of residence } \\
\hline Muscat & $65(35.9)$ \\
\hline South Al Batinah & $16(8.8)$ \\
\hline North Al Batinah & $27(14.9)$ \\
\hline A'Dakhiliyah & $38(21.0)$ \\
\hline South Ash Sharqiyah & $6(3.3)$ \\
\hline North Ash Sharqiyah & $10(5.5)$ \\
\hline Dhofar & $6(3.3)$ \\
\hline Ad Dhahirah & $12(6.6)$ \\
\hline Al Buraimi & $1(0.6)$ \\
\hline \multicolumn{2}{|l|}{ Employment status } \\
\hline Unemployed & $105(58.0)$ \\
\hline Employed & $41(22.7)$ \\
\hline Retired & $35(19.3)$ \\
\hline \multicolumn{2}{|l|}{ Monthly family income in OMR } \\
\hline$\leq 500$ & $102(56.4)$ \\
\hline $501-1,000$ & $52(28.7)$ \\
\hline $1,001-2,000$ & $26(14.4)$ \\
\hline$\geq 2,001$ & $1(0.6)$ \\
\hline
\end{tabular}

$O M R=$ Omani rials; $B C=$ breast cancer

"Information from one patient is missing $(n=180)$. ${ }^{\dagger}$ According to the education system in Oman. ${ }^{\neq}$Information from four patients are missing $(n=177)$. 
Table 3: Perceived level of unmet supportive care needs* in each domain among Omani women diagnosed with breast cancer $(\mathrm{N}=181)$

\begin{tabular}{|c|c|c|c|c|c|c|}
\hline \multirow[t]{3}{*}{ Domain } & \multirow[t]{3}{*}{ Item } & \multicolumn{5}{|c|}{ n (\%) } \\
\hline & & \multicolumn{5}{|c|}{ Perceived level of unmet need } \\
\hline & & $\begin{array}{l}\text { No need/ } \\
\text { not } \\
\text { applicable }\end{array}$ & $\begin{array}{l}\text { No need/ } \\
\text { satisfied }\end{array}$ & Low & Moderate & High \\
\hline \multirow[t]{10}{*}{ Psychological } & Fears about loss of independence & $73(40.3)$ & $38(21.0)$ & $33(18.2)$ & $28(15.5)$ & $9(5.0)$ \\
\hline & Feeling depressed/sad & $64(35.4)$ & $30(16.6)$ & $35(19.3)$ & $25(13.8)$ & $27(14.9)$ \\
\hline & Fears about pain & $37(20.4)$ & $28(15.5)$ & $50(27.6)$ & $43(23.8)$ & $23(12.7$ \\
\hline & Fears about cancer spreading & $30(16.6)$ & $22(12.2)$ & $32(17.7)$ & $36(19.9)$ & $61(33.7)$ \\
\hline & Fears about cancer recurrence & $28(15.5)$ & $28(15.5)$ & $31(17.1)$ & $32(17.7)$ & $62(34.3)$ \\
\hline & $\begin{array}{l}\text { Accepting changes to your body/ } \\
\text { appearance }\end{array}$ & $22(12.2)$ & $82(45.3)$ & $24(13.3)$ & $28(15.5)$ & $25(13.8)$ \\
\hline & Thinking about death & $69(38.1)$ & $47(26.0)$ & $20(11.0)$ & $24(13.3)$ & $21(11.6)$ \\
\hline & Fears about lifestyle changes & 54. (29.8) & $42(23.2)$ & $39(21.5)$ & $24(13.3)$ & $22(12.2)$ \\
\hline & $\begin{array}{c}\text { Concerns regarding the ability of } \\
\text { those close to you to cope with your } \\
\text { care }\end{array}$ & $73(40.3)$ & $37(20.4)$ & $33(18.2)$ & $17(9.4)$ & $21(11.6)$ \\
\hline & $\begin{array}{l}\text { Fears about your children or those } \\
\text { close to you }\end{array}$ & $43(23.8)$ & $23(12.7)$ & $26(14.4)$ & $30(16.6)$ & $59(32.6)$ \\
\hline \multirow{5}{*}{$\begin{array}{l}\text { Physical and } \\
\text { daily living }\end{array}$} & Pain & $28(15.5)$ & $39(21.5)$ & $50(27.6)$ & $46(25.4)$ & $18(9.9)$ \\
\hline & Tiredness & $19(10.5)$ & $38(21.0)$ & $48(26.5)$ & $53(29.3)$ & $23(12.7)$ \\
\hline & Nausea/vomiting & $65(35.9)$ & $26(14.4)$ & $36(19.9)$ & $36(19.9)$ & $18(9.9)$ \\
\hline & Not sleeping well & $42(23.2)$ & $22(12.2)$ & $41(22.7)$ & $47(26.0)$ & $29(16.0)$ \\
\hline & $\begin{array}{l}\text { Not able to do the things that you } \\
\text { could before the cancer diagnosis }\end{array}$ & $38(21.0)$ & $34(18.8)$ & $41(22.7)$ & $40(22.1)$ & $28(15.5)$ \\
\hline \multirow[t]{8}{*}{$\begin{array}{l}\text { Health system } \\
\text { and information }\end{array}$} & $\begin{array}{l}\text { Need to talk to someone who } \\
\text { understands and has experience } \\
\text { with your case }\end{array}$ & $19(10.5)$ & $41(22.7)$ & $34(18.8)$ & $30(16.6)$ & $57(31.5)$ \\
\hline & $\begin{array}{l}\text { Need for more information about } \\
\text { your diagnosis and prognosis (i.e. } \\
\text { your future condition) }\end{array}$ & $19(10.5)$ & $48(26.5)$ & $20(11.0)$ & $33(18.2)$ & $61(33.7)$ \\
\hline & $\begin{array}{l}\text { Need to be informed about available } \\
\text { treatments and their benefits and } \\
\text { side effects }\end{array}$ & $14(7.7)$ & 44. (24.3) & $22(12.2)$ & $29(16.0)$ & $72(39.8)$ \\
\hline & $\begin{array}{l}\text { Need for information about how to } \\
\text { manage your illness and side effects } \\
\text { at home }\end{array}$ & $26(14.4)$ & $34(18.8)$ & $31(17.1)$ & $40(22.1)$ & $50(27.6)$ \\
\hline & $\begin{array}{l}\text { Need for an explanation regarding } \\
\text { any tests that you undergo }\end{array}$ & $15(8.3)$ & $47(26.0)$ & $21(11.6)$ & $33(18.2)$ & $65(35.9)$ \\
\hline & $\begin{array}{l}\text { Need to be informed about what } \\
\text { you can do to help yourself get well }\end{array}$ & $19(10.5)$ & $40(22.1)$ & $20(11.0)$ & $28(15.5)$ & $74(40.9)$ \\
\hline & $\begin{array}{l}\text { Need to be informed about support } \\
\text { groups }\end{array}$ & 35 (19.3) & $32(17.7)$ & 31 (17.1) & $35(19.3)$ & $48(26.5)$ \\
\hline & $\begin{array}{l}\text { Need for access to professional } \\
\text { counselling }\end{array}$ & $51(28.2)$ & $31(17.1)$ & $32(17.7)$ & $26(14.4)$ & 41 (22.7) \\
\hline \multirow[t]{2}{*}{$\begin{array}{l}\text { Patient care and } \\
\text { support }\end{array}$} & $\begin{array}{l}\text { Need for promptness in clinical } \\
\text { appointments }\end{array}$ & 44. (24.3) & $50(27.6)$ & $29(16.0)$ & $23(12.7)$ & 35 (19.3) \\
\hline & $\begin{array}{l}\text { Need for the hospital to protect } \\
\text { your privacy }\end{array}$ & $18(9.9)$ & $70(38.7)$ & $10(5.5)$ & $24(13.3)$ & 59 (32.6) \\
\hline
\end{tabular}

"Self-assessed using a previously validated Arabic version of the 34-item Supportive Care Needs Survey-Short Form. Items were scored in terms of perceived level of need for additional support on a 5-point scale as either 1 (no need/not applicable), 2 (no need/satisfied), 3 (low need), 4 (moderate need) or 5 (high need). ${ }^{15}$ 
Table 3 (contd.): Perceived level of unmet supportive care needs* in each domain among Omani women diagnosed with breast cancer $(\mathrm{N}=181)$

\begin{tabular}{|c|c|c|c|c|c|c|}
\hline \multirow[t]{3}{*}{ Domain } & \multirow[t]{3}{*}{ Item } & \multicolumn{5}{|c|}{ n (\%) } \\
\hline & & \multicolumn{5}{|c|}{ Perceived level of unmet need } \\
\hline & & $\begin{array}{c}\text { No need/ } \\
\text { not } \\
\text { applicable }\end{array}$ & $\begin{array}{l}\text { No need/ } \\
\text { satisfied }\end{array}$ & Low & Moderate & High \\
\hline \multirow[t]{4}{*}{$\begin{array}{l}\text { Patient care and } \\
\text { support }\end{array}$} & $\begin{array}{l}\text { Need for more choice about which } \\
\text { hospital you attend }\end{array}$ & $41(22.7)$ & $56(30.9)$ & $26(14.4)$ & $25(13.8)$ & $33(18.2)$ \\
\hline & $\begin{array}{l}\text { Need for clinicians to attend } \\
\text { promptly to your physical needs }\end{array}$ & $23(12.7)$ & $67(37.0)$ & $15(8.3)$ & $27(14.9)$ & $49(27.1)$ \\
\hline & $\begin{array}{l}\text { Need for clinicians to show } \\
\text { sensitivity to your emotional needs }\end{array}$ & $19(10.5)$ & $65(35.9)$ & $12(6.6)$ & $30(16.6)$ & $55(30.4)$ \\
\hline & $\begin{array}{l}\text { Need for clinicians to be more } \\
\text { sincere with you }\end{array}$ & $20(11.0)$ & $62(34.3)$ & $13(7.2)$ & $20(11.0)$ & $66(36.5)$ \\
\hline \multirow[t]{2}{*}{ Sexuality } & Changes in your sexual feelings & $73(40.3)$ & $42(23.2)$ & $29(16.0)$ & $19(10.5)$ & $18(9.9)$ \\
\hline & Changes in your sexual relationship & $79(43.6)$ & 35 (19.3) & $25(13.8)$ & $24(13.3)$ & $18(9.9)$ \\
\hline \multirow[t]{3}{*}{ Other needs } & $\begin{array}{l}\text { Need to talk with other people who } \\
\text { have experienced cancer }\end{array}$ & $41(22.6)$ & $58(32.0)$ & $31(17.1)$ & $32(17.7)$ & $19(10.5)$ \\
\hline & Need for economic help & $75(41.4)$ & $28(15.5)$ & $23(12.7)$ & $22(12.2)$ & $33(18.2)$ \\
\hline & Need to receive less commiseration & $69(38.1)$ & $32(17.7)$ & $19(10.5)$ & $12(6.6)$ & $49(27.1)$ \\
\hline
\end{tabular}

"Self-assessed using a previously validated Arabic version of the 34-item Supportive Care Needs Survey-Short Form. ${ }^{8}$ Items were scored in terms of perceived level of need for additional support on a 5-point scale as either 1 (no need/not applicable), 2 (no need/satisfied), 3 (low need), 4 (moderate need) or 5 (high need). ${ }^{15}$

incorporating the social, spiritual, educational and informational needs of cancer patients-require a substantial improvement in most healthcare systems; moreover, until such services are easily available and accessible, the needs of cancer patients will continue to go unfulfilled. ${ }^{3}$ Nonetheless, although there were slight variations between different domains of supportive care needs in this study, the Omani women demonstrated a need for additional support across most domains, with the greatest unmet needs attributed to the domain of health system and information. When a domain is reported to have a high prevalence of unmet needs, the provision of related services in this area is commonly perceived to be insufficient; therefore, future work should be aimed at improving these services for the population. ${ }^{18}$

Cancer patients often report high levels of unmet supportive care needs concerning information and communication; in particular, many patients express a desire for further information regarding the short- and long-term implications of cancer, the management of their illness and the effectiveness and side-effects of potential treatments. ${ }^{7,19,20}$ Similarly, many of the women in the current study reported high unmet needs for more information regarding what they could do to help themselves and further explanation regarding tests, disease prognosis and the benefits and side-effects of different treatment options.
In general, cancer patients often seek additional information to assuage anxiety associated with the uncertainty of living with cancer, particularly concerning the type of cancer, its stage and potential side effects of cancer prognosis and management. ${ }^{20}$ Several factors have been found to influence cancer patients' needs for cancer-related information, including time since diagnosis, the chosen treatment, cancer stage, disease severity and the role of the patient in the treatment decision-making process. ${ }^{20}$ Approximately one-third of patients in the present study expressed fear regarding cancer recurrence and spread as well as fear for their children and loved ones, ranking these unmet needs highest in the psychological domain. Failure to identify and address topics of concern among cancer patients through informational support and resource availability can result in depression, anxiety and feelings of fear. ${ }^{18,21}$ Insufficient time for adequate information provision during consultations may also exacerbate unmet supportive care needs in the information and psychological domains. ${ }^{19}$

Patient-physician interaction is central to the process of healthcare delivery, in conjunction with adequate informational support associated with various desirable health outcomes for cancer patients. ${ }^{22}$ In addition, good physician-patient communication helps ensure an effective working relationship. ${ }^{23}$ However, patients in the current study reported a high 
Table 4: Associations between sociodemographic and clinical variables and total mean score for perceived unmet supportive care needs* among Omani women diagnosed with breast cancer $(\mathrm{N}=181)$

\begin{tabular}{|c|c|c|}
\hline Variable & Mean score \pm SEM & $P$ value \\
\hline \multicolumn{2}{|l|}{ Age in years } & \multirow[t]{5}{*}{0.855} \\
\hline$\leq 40$ & $100.98 \pm 27.79$ & \\
\hline $41-50$ & $99.51 \pm 25.34$ & \\
\hline $51-60$ & $96.17 \pm 31.98$ & \\
\hline$>60$ & $101.26 \pm 26.13$ & \\
\hline \multicolumn{2}{|l|}{ Education level $^{\dagger}$} & \multirow[t]{7}{*}{0.800} \\
\hline $\begin{array}{l}\text { Illiterate (cannot read } \\
\text { or write) }\end{array}$ & $99.50 \pm 22.85$ & \\
\hline $\begin{array}{l}\text { Completed primary } \\
\text { school (grade 6) }\end{array}$ & $105.70 \pm 28.38$ & \\
\hline $\begin{array}{l}\text { Completed } \\
\text { intermediate school } \\
\text { (grade 9) }\end{array}$ & $97.08 \pm 26.21$ & \\
\hline $\begin{array}{l}\text { Completed secondary } \\
\text { school (grade 12) }\end{array}$ & $99.37 \pm 28.28$ & \\
\hline Completed university & $97.18 \pm 29.17$ & \\
\hline $\begin{array}{l}\text { Completed } \\
\text { postgraduate/ } \\
\text { doctorate }\end{array}$ & $109.40 \pm 26.03$ & \\
\hline \multicolumn{2}{|l|}{ Marital status } & \multirow[t]{5}{*}{0.509} \\
\hline Married & $100.50 \pm 27.75$ & \\
\hline Single & $94.00 \pm 31.27$ & \\
\hline Widowed & $89.58 \pm 24.33$ & \\
\hline Divorced & $100.92 \pm 24.78$ & \\
\hline \multicolumn{2}{|l|}{ Employment status } & \multirow[t]{4}{*}{0.209} \\
\hline Unemployed & $99.45 \pm 26.99$ & \\
\hline Employed & $104.39 \pm 26.91$ & \\
\hline Retired & $93.23 \pm 28.66$ & \\
\hline \multicolumn{2}{|c|}{ Monthly family income in OMR } & \multirow[t]{4}{*}{0.136} \\
\hline$<500$ & $103.02 \pm 25.50$ & \\
\hline $501-1,000$ & $92.31 \pm 31.06$ & \\
\hline $1,001-2,000$ & $98.62 \pm 25.25$ & \\
\hline \multicolumn{2}{|l|}{ Family history of $\mathrm{BC}$} & \multirow[t]{3}{*}{0.297} \\
\hline No & $100.61 \pm 27.86$ & \\
\hline Yes & $95.72 \pm 25.91$ & \\
\hline \multicolumn{2}{|c|}{ Number of hospital visits in the last two months } & \multirow[t]{6}{*}{$0.045^{\ddagger}$} \\
\hline 1 & $94.62 \pm 27.27$ & \\
\hline 2 & $101.61 \pm 25.54$ & \\
\hline 3 & $93.14 \pm 29.20$ & \\
\hline 4 & $112.82 \pm 26.38$ & \\
\hline$>4$ & $106.36 \pm 26.34$ & \\
\hline
\end{tabular}

Time since diagnosis in years

0.403

$\leq 2$

$>2$

$101.98 \pm 25.95$

$98.25 \pm 28.01$

Stage of cancer at diagnosis

$0.047^{\ddagger}$

1

$92.11 \pm 30.24$

2

$99.50 \pm 23.47$

3 or 4

$104.32 \pm 27.24$

Treatment received in the last two months

$0.014^{\ddagger}$

$\begin{array}{ll}\text { Chemotherapy } & 109.76 \pm 24.49 \\ \text { Immunotherapy } & 102.52 \pm 26.38 \\ \text { Radiotherapy } & 110.70 \pm 24.66 \\ \text { Surgery } & 82.30 \pm 24.51 \\ \text { Combined treatment } & 88.44 \pm 26.99 \\ \text { Hormonal therapy } & 94.48 \pm 30.48 \\ \text { Other } & 96.27 \pm 26.62 \\ \text { None } & 93.50 \pm 25.19\end{array}$

$S E M=$ standard error of measurement; $O M R=$ Omani rials; $B C=$ breast cancer.

"Self-assessed using a previously validated Arabic version of the 34-item Supportive Care Needs Survey-Short Form.8 Items were scored in terms of perceived level of need for additional support on a 5-point scale as either 1 (no need/not applicable), 2 (no need/satisfied), 3 (low need), 4 (moderate need) or 5 (high need). 15 +According to the education system in Oman. $\neq$ Significant at $P<0.05$.

level of unmet needs in the patient care and support domain, especially in terms of the clinicians' lack of sincerity and sensitivity to their emotional needs. The interpersonal relationship between healthcare providers and patients plays a major role in shaping perceptions of service quality. ${ }^{24}$ Moreover, patients who feel that their treating physician is not capable of addressing the broader aspects of their care may seek information, help and advice from other sources. ${ }^{23}$

Few women in the present study prioritised certain needs related to the sharing of their experiences with others, including the need to be informed about support groups, to talk with other cancer patients/ survivors or for access to professional counselling services. In Western countries, support groups are often perceived by cancer patients to be very important, as they provide many benefits, including a greater sense of control over cancer and its treatment. ${ }^{19}$ On the other hand, cancer patients in Oman and other Arab Islamic countries often rely more heavily on family members to support them, especially when dealing with the side-effects of chemotherapy. ${ }^{3,4}$ In general, family members in Oman demonstrate a greater degree of involvement in the treatment decision-making process, a finding which may be 
exacerbated by the patients' poor communication with their oncologists. ${ }^{25}$

In Western countries, women with $\mathrm{BC}$ have reported feelings of fear, anxiety and guilt during and after cancer treatment, which affects communication with their partners and interferes with sexual activity. ${ }^{26}$ However, few Omani women in the current study perceived a high level of unmet need for additional support in the sexuality domain, despite previous research indicating that women in this population are concerned with potential bodily disfigurement, alopecia and loss of femininity as a result of surgical intervention and chemotherapy. ${ }^{12}$ However, previous studies conducted in other Islamic countries such as Malaysia and the UAE have similarly found the sexuality domain to be ranked low in terms of priority compared to other domains. ${ }^{8,16}$ As in other conservative communities, Omani women are often embarrassed and reluctant to explore their sexual needs and concerns with healthcare professionals, as such topics are considered taboo due to cultural norms. ${ }^{27}$ Furthermore, it is not considered routine practice to assess the sexual well-being of cancer patients in Oman. Healthcare professionals may not have the knowledge and skills necessary to do so; moreover, some may believe that such issues fall outside the scope of their professional responsibilities and could carry legal ramifications. ${ }^{26}$

The present study reported significant associations between total mean scores and various sociodemographic and clinical variables. In particular, women who had visited the hospital more frequently in the two months preceding the study, those diagnosed with $\mathrm{BC}$ at more advanced stages and patients receiving chemotherapy or radiotherapy demonstrated significantly higher total mean scores for unmet supportive care needs compared to their respective counterparts. Previous studies have shown that most unmet supportive care needs for cancer patients occur during the treatment phase. ${ }^{5,28}$ Surgical or medical treatments for cancer often result in serious physical side-effects and complications as well as negative psychosocial outcomes. ${ }^{29}$ Moreover, if their informational needs are not met, cancer patients are more likely to become anxious and depressed, which can worsen their health status. ${ }^{30}$ Thus, adequate informational and psychosocial support should be provided to cancer patients to help them cope with symptoms at different stages of treatment. ${ }^{28}$

Certain limitations to the current study should be acknowledged. First, although the questionnaire used in this study was originally intended to be selfcompleted by the participants or administered by research assistants to illiterate participants, due to the risk of COVID-19 cross-infection, the tool was modified so that it could be administered online. This could have impacted the patients' responses. Moreover, the occurrence of a global pandemic and disruptions to normal cancer service provisions at the time of the study may have affected perceptions of unmet supportive care needs among the respondents. Second, although the current study reported a significant association between women who received chemotherapy or radiotherapy and higher total mean scores for unmet supportive care needs, other factors may have played a role in these findings. Psychological or emotional distress, as well as other variables such as age, education level, family history of BC, access to information and financial status might all have a strong bearing on a patient's perceptions and concerns regarding their unmet needs. Thus, further research utilising more objective measures and evaluation tools and with a larger sample size is needed to rule out such negative associations. Third, future research evaluating the unmet supportive care needs of women with $\mathrm{BC}$ in Oman should consider the impact of their level of involvement in the decision-making process and the influence and perceptions of other family members, particularly male family members, as well as other psychosocial aspects of attitudes to health, such as the stigma associated with a BC diagnosis and the patient's own level of knowledge regarding their diagnosis, stage of disease and health outcome. Finally, participants were recruited from one of two main oncology treatment centres in Oman; therefore, differences in findings between the two centres cannot be ruled out.

\section{Conclusion}

Despite slight variations between different domains, this study found that the majority of unmet supportive care needs among Omani women with BC were informational in nature. As such, there is an urgent need to improve informational support services at SQUH. In addition, physicians should consider adopting a patient-centred care approach during consultations. This should include exploring the concerns and expectations of the patient at various stages of the cancer care process, including the shortand long-term implications of cancer, their prognosis, potential side-effects of treatment and the risk of cancer among family members. Moreover, additional training should be provided to improve language barriers between patients and non-Arabic-speaking providers. 


\section{AUTHORS' CONTRIBUTION}

MA, KA, AAA, HA and AKA conceived the design of the study. AAA, HA and AKA collected the data, while SMP and SJ analysed the data. All authors participated in drafting the manuscript. All authors approved the final version of the manuscript.

\section{ACKNOWLEDGEMENTS}

Permission to use the Arabic version of the SCNSSF34 tool utilised in this study was granted by Nair et al. ${ }^{8}$ The authors would like to thank the participants for taking part in this study as well as the authorities at the SQUH for allowing this study to be conducted.

\section{CONFLICTS OF INTEREST}

The authors declare no conflicts of interest.

\section{FUNDING}

No funding was received for this study.

\section{References}

1. Bray F, Ferlay J, Soerjomataram I, Siegel RL, Torre LA, Jemal A Global cancer statistics 2018: GLOBOCAN estimates of incidence and mortality worldwide for 36 cancers in 185 countries. CA Cancer J Clin 2018; 68:394-424. https://doi.org/10.3322/caac.21492.

2. Maguire R, Kotronoulas G, Simpson M, Paterson C. A systematic review of the supportive care needs of women living with and beyond cervical cancer. Gynecol Oncol 2015; 136:478-90. https://doi.org/10.1016/j.ygyno.2014.10.030

3. Harrison ID, Young JM, Price MA, Butow PN, Solomon MJ. What are the unmet supportive care needs of people with cancer? A systematic review. Support Care Cancer 2009; 17:1117-28. https://doi.org/10.1007/s00520-009-0615-5.

4. Al-Azri MH, Al-Awisi H, Al-Rasbi S, Al-Moundhri M. Coping with a diagnosis of breast cancer among Omani women. J Health Psychol 2014; 19:836-46. https://doi.org/10.1177/13591053134 79813.

5. Chou YH, Hsieh VCR, Chen XX, Huang TY, Shieh SH. Unmet supportive care needs of survival patients with breast cancer in different cancer stages and treatment phases. Taiwan J Obstet Gynecol 2020; 59:231-6. https://doi.org/10.1016/.t.tog.2020.01.010.

6. Li WWY, Lam WWT, Au AHY, Ye M, Law WL, Poon J, et al. Interpreting differences in patterns of supportive care needs between patients with breast cancer and patients with colorectal cancer. Psychooncology 2013; 22:792-8. https://doi. org/10.1002/pon.3068

7. Al-Bahri A, Al-Moundhri M, Al-Mandhari Z, Al-Azri M. Role of the family in treatment decision-making process for Omani women diagnosed with breast cancer. Patient Educ Couns 2019; 102:352-9. https://doi.org/10.1016/j.pec.2018.08.026.

8. Nair SC, Jaafar H, Jaloudi M, Qawasmeh K, AlMarar A, Ibrahim H. Supportive care needs of multicultural patients with cancer in the United Arab Emirates. Ecancermedicalscience 2018; 12:838. https://doi.org/10.3332/ecancer.2018.838.

9. Al-Lawati NA, Al-Bahrani BJ, Al-Raisi SS, Al-Lawati JA. Twenty-year trends of cancer incidence in Omanis, 1996-2015. Oman Med J 2019; 34:361-87.

10. Al-Lawati JA, Al-Zakwani I, Fadhil I, Al-Bahrani BJ. Cancer incidence in Oman (1996-2015). Oman Med J 2019; 34:271-3. https://doi.org/10.5001/omj.2019.55.
11. Al-Azri M, Al-Baimani $\mathrm{K}, \mathrm{Al}$-Awaisi $\mathrm{H}, \mathrm{Al}-$ Mandhari $\mathrm{Z}, \mathrm{Al}$ Khamayasi J, Al-Lawati Y, et al. Knowledge of symptoms, time to presentation and barriers to medical help-seeking among Omani women diagnosed with breast cancer: A cross-sectional study. BMJ Open 2021; 11:e43976. https://doi.org/10.1136/ bmjopen-2020-043976.

12. Al-Riyami A, Abdulhadi NN, Al-Azri M. Understanding the perceptions of Omani women regarding life after a breast cancer diagnosis. Sultan Qaboos Univ Med J 2020; 20:e360-7. https://doi.org/10.18295/squmj.2020.20.04.013.

13. Al-Azri M, Al-Awisi H, Al-Rasbi S, El-Shafie K, Al-Hinai M, Al-Habsi H, et al. Psychosocial impact of breast cancer diagnosis among Omani women. Oman Med J 2014; 29:437-44. https:// doi.org/10.5001/omj.2014.115.

14. Oman Ministry of Health. Cancer incidence in Oman 2017. From: www.moh.gov.om/en/-/-20-10 Accessed: Aug 2021.

15. Boyes A, Girgis A, Lecathelinais C. Brief assessment of adult cancer patients' perceived needs: Development and validation of the 34-item Supportive Care Needs Survey (SCNS-SF34). J Eval Clin Pract 2009; 15:602-6. https://doi.org/10.1111/j.13652753.2008.01057.x

16. Edib Z, Kumarasamy V, Binti Abdullah N, Rizal AM, AlDubai SAR. Most prevalent unmet supportive care needs and quality of life of breast cancer patients in a tertiary hospital in Malaysia. Health Qual Life Outcomes 2016; 14:26. https://doi. org/10.1186/s12955-016-0428-4.

17. Heckel L, Fennell KM, Reynolds J, Osborne RH, Chirgwin J, Botti $\mathrm{M}$, et al. Unmet needs and depression among carers of people newly diagnosed with cancer. Eur J Cancer 2015; 51:2049-57. https://doi.org/10.1016/j.ejca.2015.06.129.

18. Moghaddam N, Coxon H, Nabarro S, Hardy B, Cox K. Unmet care needs in people living with advanced cancer: A systematic review. Support Care Cancer 2016; 24:3609-22. https://doi. org/10.1007/s00520-016-3221-3.

19. Ussher J, Kirsten L, Butow P, Sandoval M. What do cancer support groups provide which other supportive relationships do not? The experience of peer support groups for people with cancer. Soc Sci Med 2006; 62:2565-76. https://doi.org/10.1016/j.socsci med.2005.10.034.

20. Mekuria AB, Erku DA, Belachew SA. Preferred information sources and needs of cancer patients on disease symptoms and management: A cross-sectional study. Patient Prefer Adherence 2016; 10:1991-7. https://doi.org/10.2147/PPA.S116463.

21. Hawkins NA, Pollack LA, Leadbetter S, Steele WR, Carroll J, Dolan JG, et al. Informational needs of patients and perceived adequacy of information available before and after treatment of cancer. J Psychosoc Oncol 2008; 26:1-16. https://doi.org/10.13 00/J077v26n02_01.

22. Maly RC, Leake B, Silliman RA. Health care disparities in older patients with breast carcinoma: Informational support from physicians. Cancer 2003; 97:1517-27. https://doi.org/10.1002/ cncr.11211.

23. Adamson $M$, Choi $K$, Notaro $S$, Cotoc $C$. The doctorpatient relationship and information-seeking behavior: Four orientations to cancer communication. I Palliat Care 2018; 33:79-87. https://doi.org/10.1177/0825859718759881.

24. Padma P, Rajendran C, Lokachari PS. Service quality and its impact on customer satisfaction in Indian hospitals: Perspectives of patients and their attendants. Benchmarking 2010; 17:807-41. https://doi.org/10.1108/14635771011089746.

25. Al-Bahri A, Al-Moundhri M, Al-Mandhari Z, Al-Azri M. The role of patients' families in treatment decision-making among adult cancer patients in the Sultanate of Oman. Eur J Cancer Care (Engl) 2018; 27:e12845. https://doi.org/10.1111/ ecc. 12845 .

26. Stilos K, Doyle C, Daines P. Addressing the sexual health needs of patients with gynecologic cancers. Clin J Oncol Nurs 2008; 12:457-63. https://doi.org/10.1188/08.CJON.457-463. 
27. Wahba M. Adolescents' sexual and reproductive health in the Arab world. In: Laher E (Ed). Handbook of Healthcare in the Arab World. Berlin, Germany: Springer, 2019. Pp. 1-25. https:// doi.org/10.1007/978-3-319-74365-3_100-1.

28. Smith A, Hyde YM, Stanford D. Supportive care needs of cancer patients: A literature review. Palliat Support Care 2015; 13:1013-17. https://doi.org/10.1017/S1478951514000959.
29. Walker LG, Eremin O. Psychological assessment and intervention: Future prospects for women with breast cancer. Semin Surg Oncol 1996; 12:76-83. https://doi.org/10.1002/(sici)1098-2388(1 99601/02)12:1<76::aid-ssu11>3.3.co;2-y.

30. Whelan TJ, Mohide EA, Willan AR, Arnold A, Tew M, Sellick S, et al. The supportive care needs of newly diagnosed cancer patients attending a regional cancer center. Cancer 1997; 80:1518-24. https://doi.org/10.1002/(sici)1097-0142(199 71015)80:8<1518::aid-cncr21>3.0.co;2-7. 